\title{
Modification of the Role of a Teacher Under the Conditions of Distance Learning
}

\author{
https://doi.org/10.3991/ijet.v16i21.25675 \\ Ekaterina Viktorovna Otts ${ }^{1}$, Elena Pavlovna Panova ${ }^{1}(\varpi)$, \\ Yuliya Vladimirovna Lobanova ${ }^{1}$, Natalya Victorovna Bocharnikova ${ }^{2}$ \\ Valentina Michailovna Panfilova ${ }^{3}$, Aleksey Nikolaevich Panfilov ${ }^{3}$ \\ ${ }^{1}$ Moscow Polytechnic University, Moscow, Russia \\ ${ }^{2}$ Volgograd State Social Pedagogical University, Volgograd, Russia \\ ${ }^{3}$ Elabuga Institute of KFU, Elabuga, Russian Federation \\ panova ep@mail.ru
}

\begin{abstract}
The article examines features of the modification of the role of a teacher in higher education in connection with digitalization of education in the period before the pandemic, and during the transition of the university to a forced remote mode under the conditions of the pandemic. The assessment of effectiveness of distance learning from the point of view of students and teachers is given. The purpose of the article is to determine expectations, the degree and nature of the influence of a teacher's personality on the effectiveness of educational process in general and distance learning in particular. Researching the effectiveness of higher education in the digital age and assessing the impact on teacher effectiveness involves the use of a number of scientific principles and research methods, theoretical and empirical. To achieve the goal, the scientific works of leading foreign and Russian scientists on the problems of digitalization of education, dehumanization of education, transformation of the role of a teacher have been analyzed, and our own research has been carried out on the basis of the Moscow Polytechnic University in the form of a survey. The assessment of emotional consequences of isolation is given. The analysis of the effectiveness of distance learning, from the point of view of higher education teachers and students has been carried out.
\end{abstract}

Keywords - higher education, digitalization, education efficiency, distance learning

\section{$1 \quad$ Introduction}

Educational institutions in 2020-2021, due to the well-known events, faced a vital need to organize their main activities using distance learning systems built on the basis of e-learning or distance educational technologies. So, we globally and urgently entered another era - the era of digitalization. Such a sharp transition to distance learning in education has entailed a lot of organizational, economic, methodological, and mental 
changes. The main task for higher education remains to preserve the quality of education. The question of effectiveness of education is still open, even from the point of view of its assessment (Evans-Amalu and Claravall, 2021; Kalimullina et al., 2021).

In this regard, the transformation of the role of a teacher in the process of distance learning and the assessment of a teacher's influence on the effectiveness of training are especially interesting. In our opinion, the role of a teacher is being transformed, becoming more significant and accompanied by expansion of the functions performed (Gapsalamov et al., 2020; Williams et al., 2021; Deryagin et al., 2019; Shurygin and Krasnova, 2017; Shurygin et al., 2021; Volkova et al., 2020; Koroleva et al., 2021).

\section{Methods}

Design of research. The study of the influence of a teacher's personality on the effectiveness of learning had been and was carried out in the period $2020-2021$, that is, before the pandemic and during the pandemic. The hypothesis of the study is the assumption that the effectiveness of full-time and distance learning has a number of significant differences, in particular, regarding transformation of a teacher's role. The study of the effectiveness of distance learning was carried out at the Moscow Polytechnic University.

To assess the effectiveness of training, the following criteria have been introduced:

- General level of students' motivation to learn

- Satisfaction with the learning process

- Attendance of different types of classes

- Academic performance evaluation

The study was carried out in 2 stages: before the introduction of distance learning (before the pandemic) and one year after the introduction of distance learning.

The research was carried out using theoretical methods of scientific knowledge, as well as a number of empirical methods for collecting and processing the data. A questionnaire survey was chosen as the main empirical method. Quantitative data processing was carried out using standard mathematical methods of data analysis.

In the future, the authors plan to expand the study, that is, to conduct it on the basis of another university to compare the results and conduct the third stage of the study after the formation of a new sustainable education system, i.e. transition of students to full-time education or combined full-time and distance learning.

Population and Sample. As respondents of the study, 200 students of the Moscow Polytechnic University and 30 teachers took part. According to the criteria, the students were divided into the following groups: full-time / part-time students, working / not working, students having predominantly humanities / students having predominantly mathematical and technical subjects. 


\section{Results and discussion}

The first results of the emergency transition of the higher education system to a distance way are being studied these days from pedagogical, social, economic and other points of view. From the economic and social points of view, there is, no doubt, a large number of advantages, they are: a positive economic effect and an increase in the availability of education.

From the economic point of view, such technologies will significantly increase the profitability of educational organizations. For example, they will reduce teachers' training expenditure and labour costs, reduce utility bills associated with the maintenance of classrooms, remove the problem of modernizing existing campuses for the educational process and cancel the construction of new ones (Ableev, 2021).

However, such an emergency transition instead of the expected and discussed psychological bonuses in the form of: a decrease in the psychological pressure on students associated with their direct interaction with a teacher; increase in the level of students' motivation through the use of the wide capabilities of the virtual environment; modeling of the situation of success, which positively affects the self-perception and selfesteem of the student and more effective mastering of the educational material (Ableev, 2021) has led to a situation of psychological unpreparedness. "The regional system of higher education was not ready for a sharp transition from a standard format of education to distance learning. We are not even talking about the technical side of the issue, although there are also a large number of problems and shortcomings. The lack of readiness turned out to be psychological, both on the part of teachers and on the part of students, who did not fully accept this format of education as a fully-fledged alternative" (Volkov, 2020).

We agree with our colleagues and believe that we can observe a similar result in Moscow, in corroboration of it we have a number of open letters and complaints from students in many universities in Moscow.

We analyzed the emotional state of students during the forced isolation and received, in general, quite expected results.

The majority of students (79\%) consciously felt changes in their emotional state.

And this shift of mood took a negative direction among $30 \%$ of respondents and to a positive direction among $51 \%$ of respondents.

Concerning negative emotions, there is a correlation between the lack of permanent work among the interviewed students and the need for live human contact. As our research has shown, they are the students, when assessing the effectiveness of an online course, who assess the degree of a teacher participation and expect him or her to fulfill the role of a tutor.

In addition, $90 \%$ of the respondents answered that in the process of distance learning they felt the need for simple friendly communication with their teachers and elements of emotional support, sympathy and praise.

Moreover, there is an interconnection with a negative assessment of the quality of distance learning. Most of these are problems of technical nature: difficulties with opening a file, malfunctions of the distance learning system, etc. But there is also a dissatisfaction with the level of teachers' digital literacy. 
The influence of a teacher's personality on students' motivation

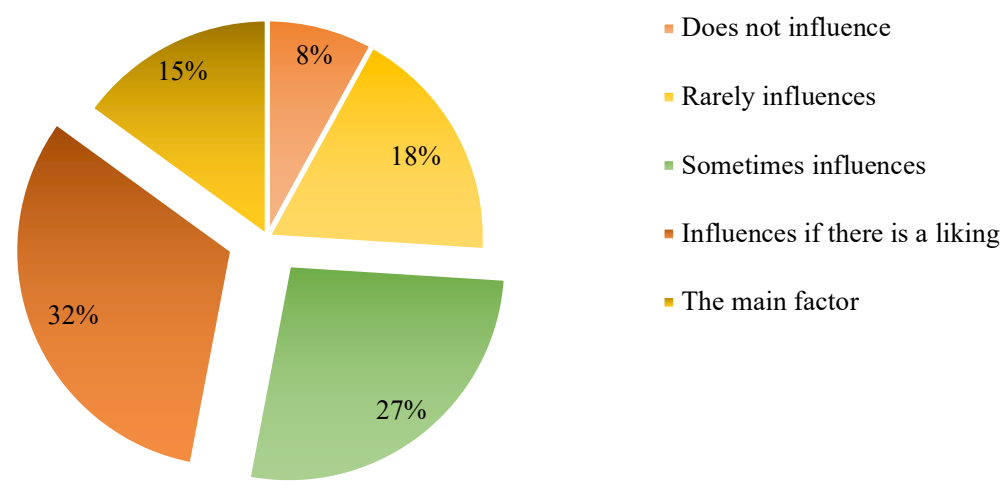

Fig. 1. Human factors and motivation to involve in distance educational process during isolation

An expert survey of teachers showed that in the process of distance learning, the problem of maintaining external motivation was the primary and most obvious one.

An interesting fact is the assessment by students of a teacher's personality and expectations from a teacher during isolation (Fig. 1). We got an opposite result regarding positive motivation. That is, sympathy for a teacher among $59 \%$ of the respondents is the main factor when getting involved into a University course.

And here we are faced with an ethical problem that is widely discussed in the scientific community. Many world leaders in online education (Coursera, LinguaLeo, DuoLingo, etc.) are trying to regain lost motivation through the use of gaming technologies. Obviously, these methods are extremely standardized and formalized, and, therefore, they cannot solve the problem of demotivating among particular schoolchildren or students. Effective cognitive motivation is always personalized and contextual "Ableev".

It is obvious, and the study confirms it, that in a distance learning situation, the teacher loses control over motivation and is forced to choose between two evils - either lower the level of requirements and proceed following the preferences of the audience, or, using effective content, lead the audience strictly along one route without individual approach training in terms of specific students. Both are beyond the bounds of teaching ethics.

In addition, with the transition to distance learning, the content of pedagogical activity has changed significantly. Our survey of the teachers of Moscow Polytechnic University clearly showed how the functions of a teacher in higher education had changed during the transition from full-time education to distance learning (see Table 1).

We should characterize these roles.

The teacher performs the following functions: teaching, control of the academic achievements when taking the course, tracking motivation. 
The tutor functions are: full and individual support of students, including a student's independent work mentoring.

The main function of the training system administrator is to ensure the functioning of the entire system at the technical level.

The course designer accomplishes the duties of developing content and logic of learning, i.e. concept designing, selection of copyrighted materials and formation of teaching methods.

The organizer coordinates the activities of students, helps in organizing the learning process. The main function is to track the timely completion of assignments and attendance of classes according to the schedule.

The moderator performs clear functions of monitoring the training process or conducting the review of academic performances.

The student's task is to acquire knowledge and skills during the learning process. For a teacher, this is a process of self-education or pursuing new competencies.

The mentor plays the role of a mastermind, tracking students' learning motivation and reflection.

The roles of a university teacher described by us and their transformation in the process of transition to distance learning clearly demonstrates the changes in the functions of a higher school teacher. We see an increase in the roles of higher education teachers in the conditions of distance learning. It is obvious that the expansion of functions will be accompanied by either a loss of teaching efficiency or a burnout of teaching staff. We believe that the problem of expanding functions can be solved through teamwork and specifying the role for each individual teacher.

Besides, we should note that the function of the encourager (mastermind) has undergone negative changes.

Table 1. Changes in a teacher's functions during the transition to distance learning (expressed as a percentage)

\begin{tabular}{|l|c|c|}
\hline Functions & Full-time traditional education & Distance education \\
\hline Teacher & 100 & 78 \\
\hline Tutor & 30 & 87 \\
\hline Learning system administrator & 8 & 76 \\
\hline Course designer & 57 & 86 \\
\hline Organizer & 12 & 68 \\
\hline Moderator & 100 & 100 \\
\hline Student & 54 & 100 \\
\hline Mentor & 98 & 20 \\
\hline
\end{tabular}

\section{Conclusion}

The analysis of the ethical side of the issue, of the research data from colleagues and the results of our own research have led us to the following conclusion: 
- the role of a university teacher is being transformed, which leads to expansion of functional responsibilities and requires new competencies that must be mastered with incredible speed;

- -distance learning and modern digital era not only require new competencies from a professor, but also significantly transform role expectations and, accordingly, require new behavioral models;

- in the process of distance learning, there is a problem of maintaining a balance between a rigid learning strategy, where a clear route is set and absence of creative freedom and a strategy to facilitate the course for students, which reduces the quality of education;

- the curriculum of all specialties and areas of study should include humanitarian subjects which form the ability to learn and resist stress;

- one of the main competencies in the digital age is the ability to live in the digital world and, at the same time, preserve humanness, therefore, mechanisms that form human relationships and support the authority of a teacher in the education system should be laid in distance technologies.

- the structure of distance learning should provide for such ideas and forms that will allow a teacher to fulfill the role of a mentor, which is a moral imperative of the profession.

- before introducing forms of distance learning on a permanent basis additional research is needed on the effectiveness of distance learning, since the improvement in the quality of education is not obvious yet.

\section{$5 \quad$ References}

[1] Ableev S.R., \& Kuzminskaya S.I. (2021). Electronic format and dehumanization of the educational process: psychological, didactic and social aspects. Information Society. 2021. No. 1. pp. 337-340.

[2] Alekseeva D.A., \& Alekseev I.Yu. (2021). Lecturer in the context of digitalization. Bulletin of Applied Ethics. 2021. Issue 57. P. 83-92

[3] Deryagin, A. V., Krasnova, L. A., Sahabiev, I. A., Samedov, M. N., \& Shurygin, V. Y. (2019). Scientific and educational experiment in the engineering training of students in the bachelor's degree program in energy production. International Journal of Innovative Technology and Exploring Engineering, 8(8), 572-577.

[4] Evans-Amalu, K., \& Claravall, E. (2021). Inclusive Online Teaching and Digital Learning: Lessons Learned in the Time of Pandemic and Beyond. Journal Of Curriculum Studies Research, 3(1), i-iii. https://doi.org/10.46303/jcsr.2021.4

[5] Gapsalamov, A. R., Merzon, E. E., Kuznetsov, M. S., Vasilev, V. L., \& Bochkareva, T. N. (2020). The education system in the context of socio-economic transformations. [O sistema educacional no contexto das transformações socioeconômicas] Periodico Tche Quimica, 17(34), 874-883. https://doi.org/10.52571/ptq.v17.n34.2020.898 p34 pgs 874 883.pdf

[6] Kalimullina O. Tarman B., \& Stepanova I. (2021). Education in the Context of Digitalization and Culture: Evolution of the Teacher's Role, Pre-pandemic Overview. Journal of Ethnic and Cultural Studies, Vol. 8, No. 1, 226-238. https://doi.org/10.29333/ejecs/629

[7] Koroleva, N. E., Achaeva, M. S., \& Pospelova, N. V. (2021). Modern technologies in the process of determining the professional suitability of freshmen students of a teacher training 
college. International Journal of Emerging Technologies in Learning, 16(3), 235-245. https://doi.org/10.3991/ijet.v16i03.17463

[8] Shurygin, V. Y., \& Krasnova, L. A. (2017). The peculiarities of pedagogical projects implementation for identification and development of giftedness in children. Astra Salvensis, 2017, 47-54.

[9] Shurygin, V., Saenko, N., Zekiy, A., Klochko, E., \& Kulapov, M. (2021). Learning management systems in academic and corporate distance education. International Journal of Emerging Technologies in Learning, 16(11), 121-139. https://doi.org/10.3991/ijet.v16i11.20701

[10] Volkov S.K. (2020). Experience of regional universities in organizing distance learning: first results. Bulletin of the Moscow University of the Ministry of Internal Affairs of Russia. No. 4. pp. 52-62.

[11] Volkova, P. S., Orekhova, E. S., Saenko, N. R., Trofimova, L. V., \& Barova, A. G. (2020). Features of the modern process of differentiation of sense and meaning in communication. Media Watch, 11(4), 679-689. https://doi.org/10.15655/mw/2020/v11i4/204639

[12] Williams, T., McIntosh, R., \& Russell, W. (2021). Equity in Distance Education During COVID-19. Research in Social Sciences and Technology, 6(1), 1-24. https://doi.org/10. 46303/ressat.2021.1

\section{Authors}

Ekaterina Viktorovna Otts PhD in Psychology, Associated Professor, Moscow Polytechnic University, 38 Bolshaya Semyonovskaya street, Moscow, Russia, 107023 (Email: evotts@gmail.com ORCID: https://orcid.org/0000-0002-5344-9333).

Elena Pavlovna Panova Candidate of philological sciences, Associated Professor, Moscow Polytechnic University, 38 Bolshaya Semyonovskaya street, Moscow, Russia (ORCID: https://orcid.org/0000-0002-3868-3834).

Yuliya Vladimirovna Lobanova PhD in Philosophy, The head of the department «Humanitarian disciplines» of Moscow Polytechnic University, 38 Bolshaya Semyonovskaya street, Moscow, Russia (Email: Julia-lobanova@mail.ru, ORCID: https://orcid.org/0000-0003-2970-7520).

Natalya Victorovna Bocharnikova Candidate of philological sciences, Assistant professor of English Philology Department, Volgograd State Social Pedagogical University, Volgograd, Russia (Email: bocharnikoff@mail.ru ORCID https://orcid.org/ 0000-0001-9984-6214).

Valentina Michailovna Panfilova, Associate professor at German Philology Department, Kazan federal university, Elabuga Institute of KFU, Elabuga, Russian Federation (Email:v.panfilova2010@yandex.ru, ORCID: https://orcid.org/0000-0001-6844$\underline{874 X)}$.

Aleksey Nikolaevich Panfilov, Associate professor at the Psychology Department, Kazan federal university, Elabuga Institute of KFU, Elabuga, Russian Federation (Email: panfiloval@mail.ru ORCID https://orcid.org/0000-0002-9652-6570).

Article submitted 2021-07-22. Resubmitted 2021-08-23. Final acceptance 2021-08-24. Final version published as submitted by the authors. 